\begin{tabular}{l} 
SCIENCE \& TECHNOLOGY \\
Journal homepage: http://www.pertanika.upm.edu.my/ \\
\hline PERTANIKA
\end{tabular}

\title{
Combined Impacts of Predation, Mutualism and Dispersal on the Dynamics of a Four-Species Ecological System
}

\author{
Murtala Bello Aliyu ${ }^{1,2 *}$ and Mohd Hafiz Mohd ${ }^{1,3}$ \\ ${ }^{1}$ School of Mathematical Sciences, Universiti Sains Malaysia, 11800 USM, Penang, Malaysia \\ ${ }^{2}$ Department of Mathematics, Nigerian Defence Academy, Afaka, PMB 2019, Kaduna, Nigeria \\ ${ }^{3}$ School of Mathematical Sciences, Faculty of Science and Technology, Universiti Kebangsaan Malaysia, \\ 43600 UKM, Bangi, Selagor, Malaysia
}

\begin{abstract}
Multi-species and ecosystem models have provided ecologist with an excellent opportunity to study the effects of multiple biotic interactions in an ecological system. Predation and mutualism are among the most prevalent biotic interactions in the multi-species system. Several ecological studies exist, but they are based on one-or two-species interactions, and in real life, multiple interactions are natural characteristics of a multi-species community. Here, we use a system of partial differential equations to study the combined effects of predation, mutualism and dispersal on the multi-species coexistence and community stability in the ecological system. Our results show that predation provided a defensive mechanism against the negative consequences of the multiple species interactions by reducing the net effect of competition. Predation is critical in the stability and coexistence of the multi-species community. The combined effects of predation and dispersal enhance the multiple species coexistence and persistence. Dispersal exerts a positive effect on the system by supporting multiple species coexistence and stability of community structures. Dispersal process also reduces the adverse effects associated with multiple species interactions. Additionally, mutualism induces oscillatory behaviour on the system through Hopf bifurcation. The

ARTICLE INFO

Article history:

Received: 21 June 2020

Accepted: 18 September 2020

Published: 22 January 2021

DOI: https://doi.org/10.47836/pjst.29.1.13

E-mail addresses:

murtalabelloaliyu@gmail.com (Murtala Bello Aliyu)

mohdhafizmohd@usm.my (Mohd Hafiz Mohd)

* Corresponding author roles of mutualism also support multiple species coexistence mechanisms (for some threshold values) by increasing the stable coexistence and the stable limit cycle regions. We discover that the stability and coexistence mechanisms are controlled by the transcritical and Hopf bifurcation that
\end{abstract}


occurs in this system. Most importantly, our results show the important influences of predation, mutualism and dispersal in the stability and coexistence of the multi-species communities.

Keywords: Dispersal, Hopf bifurcation, limit cycle, multi-species, stability, transcritical bifurcation

\section{INTRODUCTION}

The population dynamics of multi-species systems are substantially driven by interspecific interactions (Gause \& Witt, 1935; Ojonubah \& Mohd, 2020). There has been renewed interest in the role of predation in conservation (Soulé \& Terborgh, 1999; Sala, 2006; Schmitz, 2006; Johnson et al., 2007). Several work on empirical and theoretical studies have addressed the effects of predation on the dynamics of the multi-species communities (Rosenzweig \& MacArthur, 1963; Chesson, 2000). For instance, Hixon \& Menge (1991) showed in their study that predation strength (i.e., rate at which the predator feeds on the prey) had a direct effect on the diversity of prey species. Predation in the multi-species community has been shown to preserve species coexistence when its effects are more prevalent than competitive interactions; on the other hand, predation can also lead to species exclusion (Chesson \& Kuang, 2008).

Recently, some researchers have shed some light on the dynamics of mutualistic interactions; (i.e., symbiotic interaction between two-species where each benefits from the other) (Bronstein, 2001a; Holland et al., 2002; Bever, 2003; Bruno et al., 2003). These studies of mutualism were carried out in one-or two-species system. In real life, multiple species interact in different ways. Some other studies on mutualism arrived at two generalisations (Holland et al., 2002); (i) the stability of the multi-species systems depends on how the positive feedback from mutualism is balanced with the negative feedback (Chesson, 2000; Bever, 2003); (ii) mutualism has direct cost and benefits that are dependent on density of populations (Addicott, 1979; Morales, 2000; Bronstein, 2001b). In reality, the maintenance of the ecosystem, ecological structure and biodiversity are well-known benefits that can be gained from mutualism (Aslan et al., 2013). Predation and mutualism are among important biotic interactions that occur in nature. The dynamics of these interactions are intertwined, and this has hampered the understanding of their combined effects in isolation (Fontaine et al., 2011; Georgelin \& Loeuille, 2014). Moreover, information on the combined effects of predation, mutualism and dispersal on multi-species coexistence and community stability are poorly understood, and thus warrant further studies.

Predation and mutualism have a stabilising impact on the negative feedback when species population density is abundant (Holland et al., 2002; Schmitt \& Holbrook, 2003; Holland \& DeAngelis, 2010; Holland et al., 2013). An essential ecological question is what effects dispersal has on the interplay between predation and mutualism in a fourspecies ecological system. To address this problem, we used a system of partial differential 
equations (PDE) to gain insight on the combined effects of predation, mutualism, and dispersal in the ecological systems. In general, dispersal plays a vital role in conservation biology and spatial ecology (Hanski, 1998; Kindlmann \& Burel, 2008; Kool et al., 2012). Dispersal facilitates the mobility of species to new environments (Bonte et al., 2003). Low dispersal strength has a synchronisation effect (i.e., variation in an ecological context and population dynamics) on large amplitude population cycles across space (Bjørnstad, 2000; Vasseur \& Fox, 2009; Vogwill et al., 2009). The chances for dispersal-induced stability is low when the population cycle goes through spatial synchrony (i.e., the abundance of different geographical populations) (Yaari et al., 2012; Lampert \& Hastings, 2016). Several studies have demonstrated how antagonistic interactions facilitate dispersal (Mondor et al., 2004; Green, 2009; Poethke et al., 2010; Chaianunporn \& Hovestadt, 2015; Amarasekare, 2015). A well-known effect of antagonistic interaction is strong population cycles which consequencely lead to changes in species fitness (Green, 2009; Chaianunporn \& Hovestadt, 2012).

Some studies also report that dispersal lessens the variability in species population and extinction (Briggs \& Hoopes, 2004; Vogwill et al., 2009; Abbott, 2011). Nevertheless, there are conflicting evidence on how dispersal affects the multi-species communities. Varying abundances in species population in various geographical areas are one of the benefits derives from dispersal among local populations (Kendall et al., 2000; Abbott, 2011). It has also been demonstrated that the effect of dispersal on the multi-species community could either be no effects, stabilising, or destabilising (Dey \& Joshi, 2006; Steiner et al., 2013). A more recent study shows that dispersal could have both stabilising and destabilising effect on a multi-species ecological system (Mohd et al., 2018). Given all these different perspectives on predation, mutualism, and dispersal, it becomes crucial to investigate the combined effects of predation, mutualism and dispersal on the species coexistence and community stability in these multi-species systems. In general, the joint effects of predation, mutualism and dispersal on the multi-species communities are still unclear and need to be further explored.

To cover this knowledge gap, we extended the four-species interactions model (Mitani \& Mougi, 2017) to investigate the effects of predation, mutualism, and dispersal. We numerically showed the impact of predation, mutualism and dispersal on the multiple species coexistence dynamics. Furthermore, we discussed the implications of our results from the perspectives of multiple species coexistence and community stability.

\section{MATERIAL AND METHODS}

\section{Model Description}

We proposed a system of PDE for the densities $X(x, t), W(x, t), Y(x, t)$ and $Z(x, t)$ in onedimension $0 \leq \mathrm{x} \leq 1$ (Equation 1) (Mitani \& Mougi, 2017; Mohd et al., 2017): 


$$
\begin{aligned}
& \frac{\partial X}{\partial t}=X\left(r_{k}-\mathrm{X}-\beta \mathrm{W}-a \mathrm{Y}+\frac{u Z}{h_{Z}+Z}\right)+D_{1} \frac{\partial^{2} X}{\partial x^{2}} \\
& \frac{\partial W}{\partial t}=W\left(r_{w}-\mathrm{W}-\alpha \mathrm{X}\right)+D_{2} \frac{\partial^{2} W}{\partial x^{2}} \\
& \frac{\partial Y}{\partial t}=Y(g a X-d)+D_{3} \frac{\partial^{2} Y}{\partial x^{2}} \\
& \frac{\partial Z}{\partial t}=Z\left(r_{z}-\mathrm{Z}+\frac{v X}{h_{X}+X}\right)+D_{4} \frac{\partial^{2} Z}{\partial x^{2}}
\end{aligned}
$$

where $X, W, Y, Z$ represent the population densities of resource, competitor, exploiter, and mutualist species, respectively. The parameter $r_{k}$ is the rate at which the resource species grows; $r_{w}$ is the rate at which the competitor species grows; $r_{z}$ is the rate at which the mutualist species grows; $\alpha$ and $\beta$ represent the strength of competition (i.e., resource and competitor species, respectively); $a$ represents capture rate (i.e., the rate at which the exploiter species capture the prey). The term $g$ represents the conversion efficiency; $d$ represents exploiter species death; $u$ and $v$ represent the benefits from the mutualistic interactions (i.e., mutualistic strength of the resource and mutualist species, respectively); $h_{x}$ and $h_{z}$ represent the half-saturation constant of resource and mutualist species, respectively (i.e., density at which half the average intake of prey is achieved, irrespective of the prey population available). It is assumed that the self-regulation mechanism of mutualist species (net effect of a mutualist on the other mutualist species) is unity for theoretical simplicity. Equation 1 is a spatial extension of the multiple interactions type model (Mitani $\&$ Mougi, 2017). The system of ordinary differential equations (ODE) becomes systems of PDE with the addition of the diffusion term. The term $D_{i}(i=1,2,3,4)$ represents the dispersal strength along spatial domain $(x)$. We assumed equal dispersal strength for all the interacting species $\left(D_{1}=D_{2}=D_{3}=D_{4}=0.005\right)$. Also, we applied zero-flux boundary conditions for each of the interacting species (Equation 2) (i.e., no movement is allowed across the boundaries):

$$
\begin{aligned}
& D_{1} \frac{\partial X(0, t)}{\partial x}=D_{1} \frac{\partial X(1, t)}{\partial x} \\
& D_{2} \frac{\partial W(0, t)}{\partial x}=D_{2} \frac{\partial W(1, t)}{\partial x} \\
& D_{3} \frac{\partial Y(0, t)}{\partial x}=D_{3} \frac{\partial Y(1, t)}{\partial x}
\end{aligned}
$$




$$
D_{4} \frac{\partial Z(0, t)}{\partial x}=D_{4} \frac{\partial Z(1, t)}{\partial x}
$$

To solve Equation 1 with the boundary conditions as in Equations 2, we used the method of line. This numerical approach was implemented in XPPAUT, which provides a good platform for solving PDE systems in one spatial variable $x$. The spatial domain was divided into meshes of $\mathrm{M}+1$ equivalent points of $x_{i}=i$ for $i=0,1, \ldots, \mathrm{M}(0 \leq x \leq 1)$. The central difference approximation was then employed to replace the spatial derivative in Equation 1. In this numerical method, the zero-flux boundary conditions were encoded into the scheme using finite difference approximation. The resulting transformation resulted in a $4(\mathrm{~N}+1)$ ODE scheme, one for each species at spatial location $x_{i}$. The regular ODE solver, cvode, was used for solving the resulting ODE system for $t=1000$ (i.e., until steady state). The size of the mesh used in the numerical simulation was $h=0.09$. We had also used AUTO to continue the steady state, in which case we tracked the stable, unstable and bifurcation points that arose as the parameters changed in this ecological system. It was also verified that the numerical results were insensitive to changes in grid spacing (i.e., by increasing and decreasing the number of finite difference points).

\section{RESULT}

\section{Effects of Predation on the Dynamics of ODE and PDE Models}

Here, we discuss the vital features of the system (1) in the absence of dispersal $(D=0)$. The dynamical behaviour of the ODE model (in the absence of dispersal) is represented

Table 1

Symbols, their definitions and the parameter values used for the numerical simulations

\begin{tabular}{llc}
\hline Symbol & Definition & Parameter value \\
\hline$r_{k}$ & The intrinsic growth rate of resource species & 1 \\
$r_{w}$ & The intrinsic growth rate of competitor species & 1 \\
$r_{z}$ & The intrinsic growth rate of the mutualist species & 1 \\
$u$ & Maximum benefit of the mutualistic interaction & 3 \\
$v$ & Maximum benefit of the mutualistic interaction & 2 \\
$a$ & Capture rate & 1.8 \\
$g$ & Conversion efficiency of the exploiter species & 0.25 \\
$d$ & Death rate of the exploiter & 0.05 \\
$h_{x}$ & Half saturation constant of the hyperbolic functional response & 1 \\
$h_{z}$ & Half saturation constant of the hyperbolic functional response & 1 \\
$\beta$ & Competitive strength of the competitor species & 0.7 \\
$a$ & Competitive strength of the resource species & 0.2 \\
$D$ & Dispersal strength & 0.005 \\
\hline
\end{tabular}




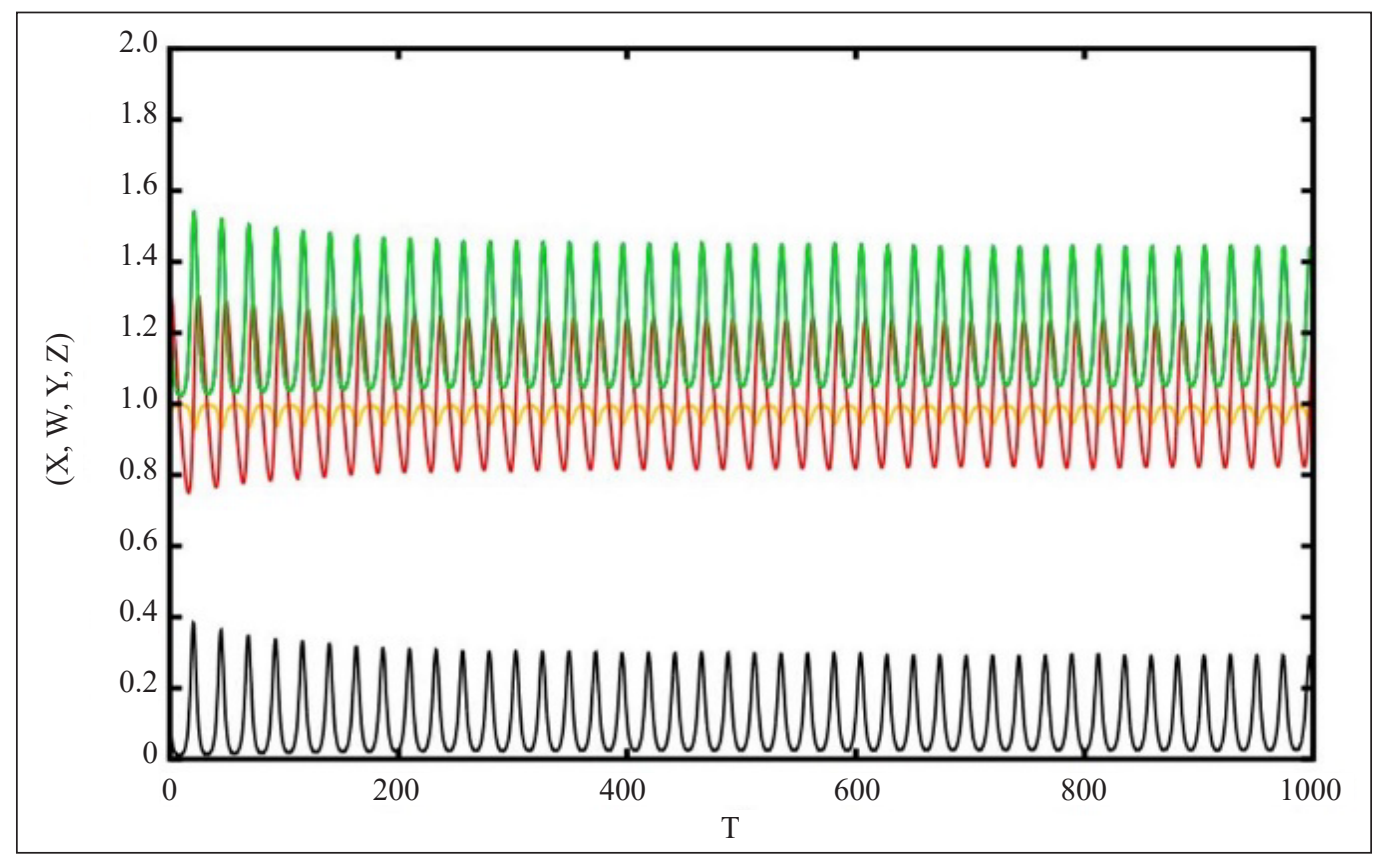

Figure 1. The time series of Equation 1 with $\mathrm{D}=0$. Initial species density $\mathrm{X}(0)=0.9, \mathrm{~W}(0)=0.3, \mathrm{Y}(0)=0.2$, $\mathrm{Z}(0)=0.8$. X (black), W (yellow), Y (red) and Z (green). The diagram was plotted using XPPAUT and the parameter values as in Table 1.

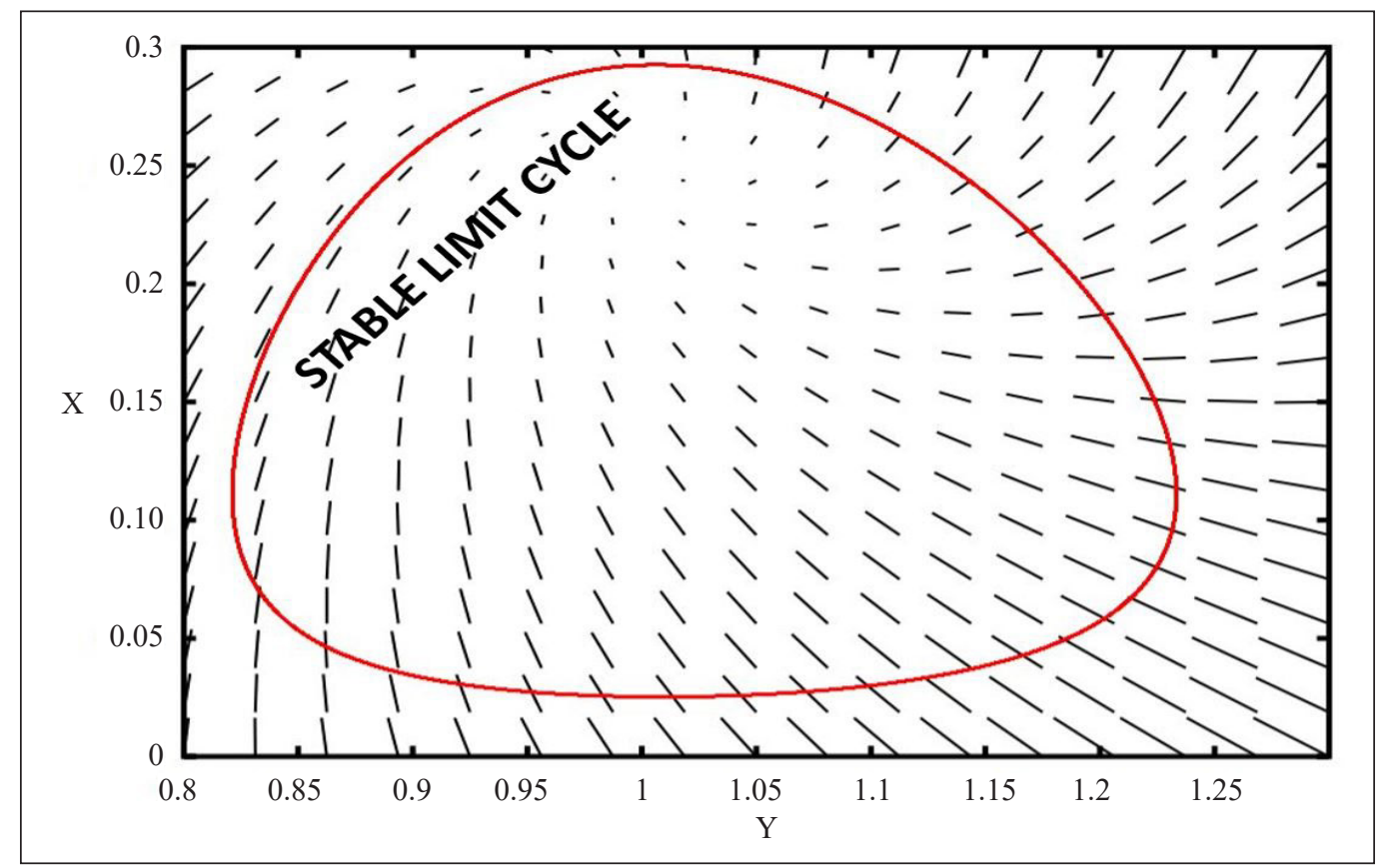

Figure 2. Stable limit cycle of Equation 1 with $\mathrm{D}=0$. Initial species density $\mathrm{X}(0)=0.9, \mathrm{~W}(0)=0.3, \mathrm{Y}(0)=$ $0.2, \mathrm{Z}(0)=0.8$. X (black), W (yellow), Y (red) and Z (green). The diagram was plotted using XPPAUT and the parameter values in Table 1. 
in Figures 1 and 2 using the parameter values as in Table 1. Figure 1 shows the oscillatory dynamics in this ecological system, which are crucial properties of multi-species interactions. This oscillatory behaviour arises due to the salient interplay of different biotic factors, i.e., resource-competitor-exploiter-mutualist interactions. Subsequently, all the steady state is unstable, and this leads to the emergence of a stable limit cycle (Figure 2 ) in which case the species population densities oscillate between some maximum and minimum densities.

Since we aimed to explore how predation and mutualism shape species coexistence and community stability, we carried out one-parameter bifurcation analysis using $a$ and $u$ (i.e., the strength of predation and mutualistic strength, respectively). For instance, Figure 3 illustrates the species population densities in the absence of dispersal as $a$ varies. There occurred a threshold point $(a=1.437)$ in this co-dimension one bifurcation (Figure 3) conforming to Hopf bifurcation (i.e., HB). This Hopf bifurcation gave births to the oscillatory behaviour in the ecological Equation 1. Thus, the strength of predation directly affects the coexistence of multiple species and the stability of community structures in this multiple interaction type system. As an example, when $a<\mathrm{HB}$, a four-species steadystate emerged and when $a>\mathrm{HB}$, stable limit cycle occurred. The transition from a fourspecies steady-state to a stable limit cycle occurred at the Hopf bifurcation point. Further, since the first Lyapunov coefficient was negative, this implies that the Hopf bifurcation is supercritical, and the limit cycle is of stable type (Figure 3).

The inclusion of dispersal qualitatively changes the dynamics of this multiple interactions type system. There occurred a critical value $(a=0.4759)$ corresponding to a transcritical bifurcation (i.e., BP) as the parameter $a$ changed in the system (Figure 4). At

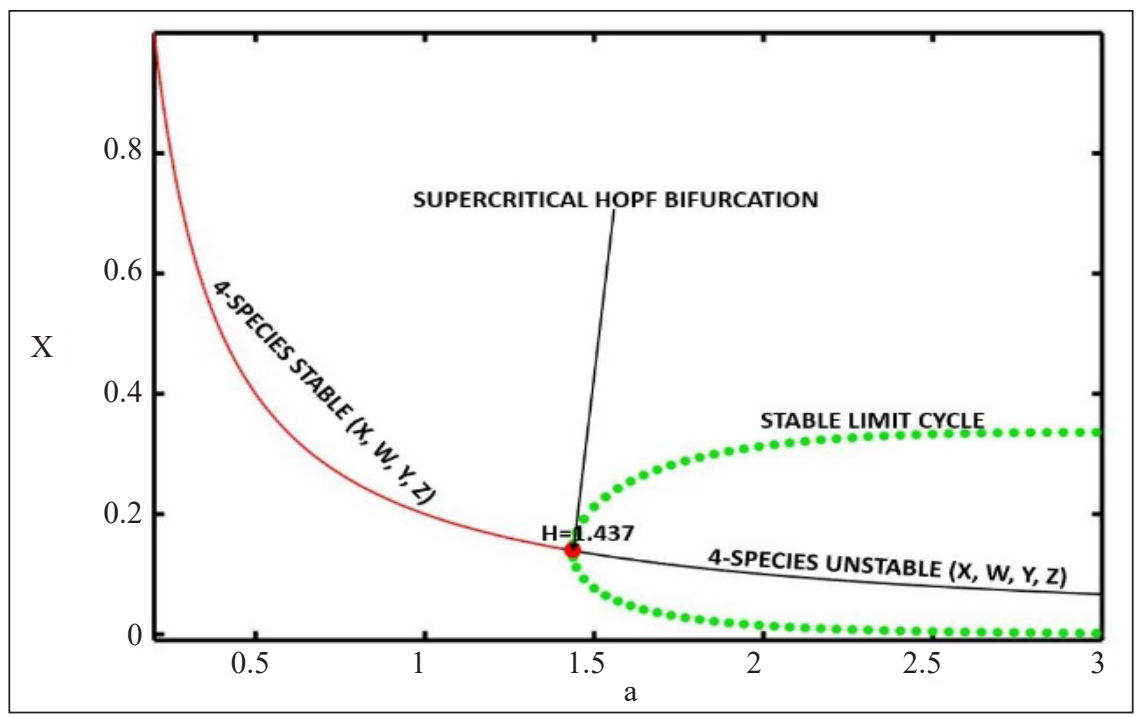

Figure 3. Bifurcation diagram showing the stability behaviour of the system as we vary a. $\mathrm{D}=0$. The diagram was plotted using XPPAUT package and the parameter values in Table 1. 


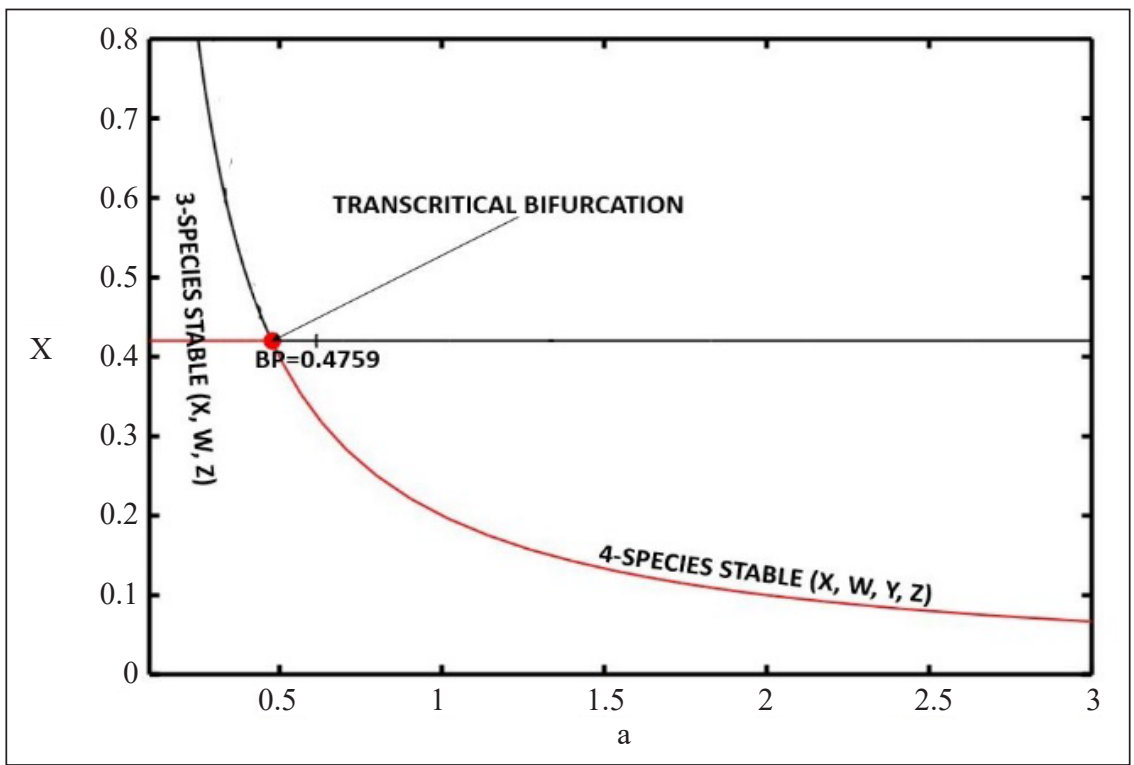

Figure 4. Bifurcation diagram showing the stability behaviour of the system as we vary a. D $=0.005$. The diagram was plotted using XPPAUT package and the parameter values in Table 1.

this transcritical bifurcation point, we observed the exchange of stability between steadystates (i.e., from three-species steady-state to four-species steady-state). The emergence of transcritical bifurcation affected species coexistence and community stability mechanisms of this ecological system. We discovered three-species steady-state (i.e., when $a<\mathrm{BP}$ ) and four-species steady-state (i.e., when $a>\mathrm{BP}$ ) as $a$ changed in the presence of dispersal (Figure 4). We also observed that weak predation strength interacted with dispersal affecting species persistence (i.e., a species goes extinct) in this multiple interactions type system. However, for the broader region of $a(a>\mathrm{BP})$, the species persistence was maintained as four-species steady-state occurred. Most importantly, this observation suggested that intense predation in the presence of dispersal supported multi-species coexistence in this ecological system. By comparing Figures 3 and 4, we observed an apparent qualitative change in the dynamics of the multiple interactions type system. Oscillatory behaviour dominated the dynamics of the ecological system without dispersal (Figure 3) and multispecies coexistence steady state dominated in the presence of dispersal (Figure 4). This result illustrates that dispersal promotes coexistence of multiple species through the occurrence of stable steady-states and also limit cycles.

\section{Effects of Mutualism on the Dynamics of ODE and PDE Models}

We first studied the effects of mutualism in the ODE system. Figure 5 shows the dynamics of the ecological system in the absence of dispersal as $u$ changes. There emerged a critical bifurcation point as the parameter $u$ (i.e., at $u=2.741$ ) varied, and this point corresponded to 
supercritical Hopf bifurcation (i.e., HB). The supercritical Hopf bifurcation affects species coexistence and community stability in this multiple interaction type model. For example, there occurred a four-species steady-state when $u<\mathrm{HB}$, and stable limit cycles when $u>$ HB. The first Lyapunov coefficient at the Hopf bifurcation point was negative; thus, this confirms that the Hopf bifurcation is supercritical and the limit cycle that emerges is stable.

In the presence of dispersal, the PDE model exhibited qualitatively similar dynamics compared to no dispersal case (Figure 6). There existed a bifurcation point that corresponded to a supercritical Hopf bifurcation (i.e., at $u=2.865$ ). The Hopf bifurcation affected multispecies composition (i.e., presence-absence of species) as $u$ changed. The first Lyapunov coefficient was negative, and this indicates that the limit cycle is stable. These species compositions include: (i) a four-species steady-state (i.e., $u<H B$ ); (ii) stable limit cycles (i.e., $u>H B$ ). We further compared the result in Figures 5 and 6 . We discovered a qualitative similar effect of dispersal which determined coexistence dynamics of this ecological system. The inclusion of dispersal shifted the threshold of mutualistic interaction strength to higher values (i.e., from $u=2.741$ to $u=2.865$ ), thus multi-species coexistence outcomes could be observed for more values of $u$. Overall, in the presence of dispersal, mutualism enhances species coexistence and community stability, compared to no-dispersal case.

We investigated the joint effects of predation and mutualism on the species coexistence and community stability by conducting a co-dimension two bifurcation analysis, as shown in Figures 7 and 8. Figure 7 depicts the effects of varying $a$ and $u$ in the absence of dispersal (i.e., $D=0$ in the Equation 1). We observed species compositions as follows: (i)

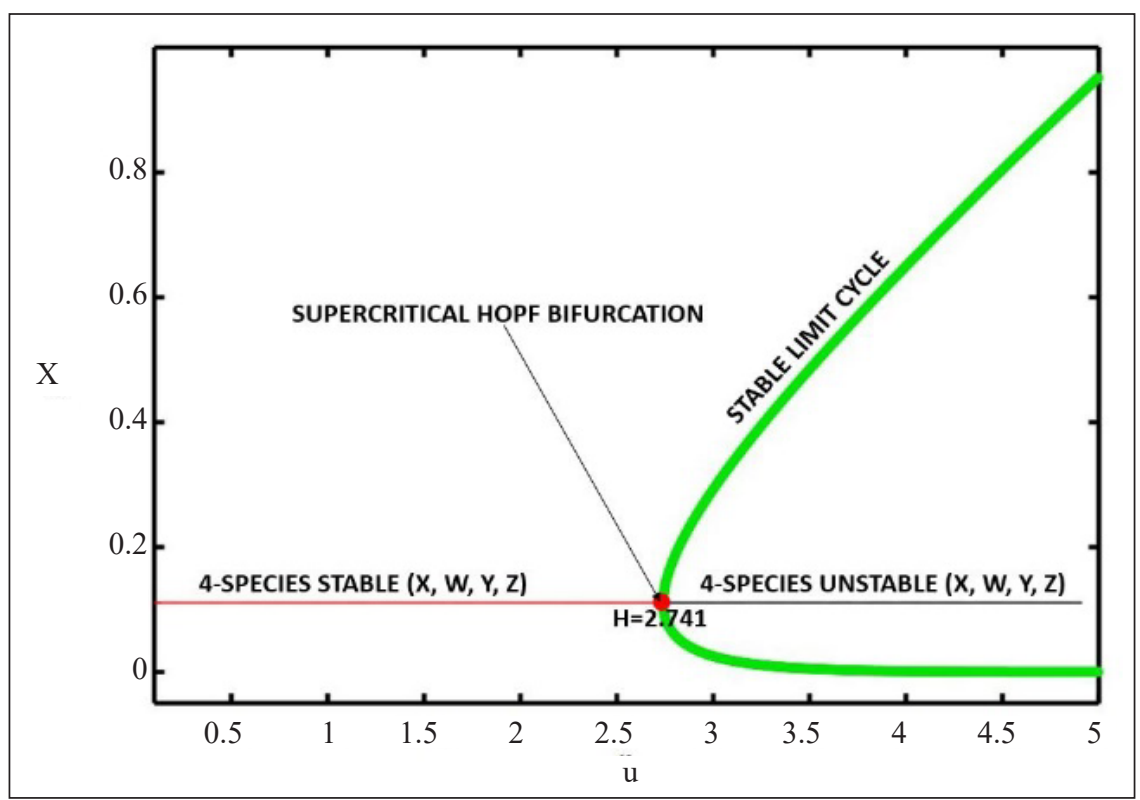

Figure 5. Bifurcation diagram showing the stability behaviour of the system as we vary $\mathrm{u} . \mathrm{D}=0$. The diagram was plotted using XPPAUT package and the parameter values in Table 1. 
four-species stable coexistence region (ii) stable limit cycles (four-species unstable) region. In the presence of dispersal (Figure 8), we had three-species stable coexistence region, four-species stable coexistence region and stable limit cycle region. Most importantly, by comparing Figures 7 and 8, we discovered that predation, mutualism, and dispersal mediate more species coexistence outcomes compared to no-dispersal case.

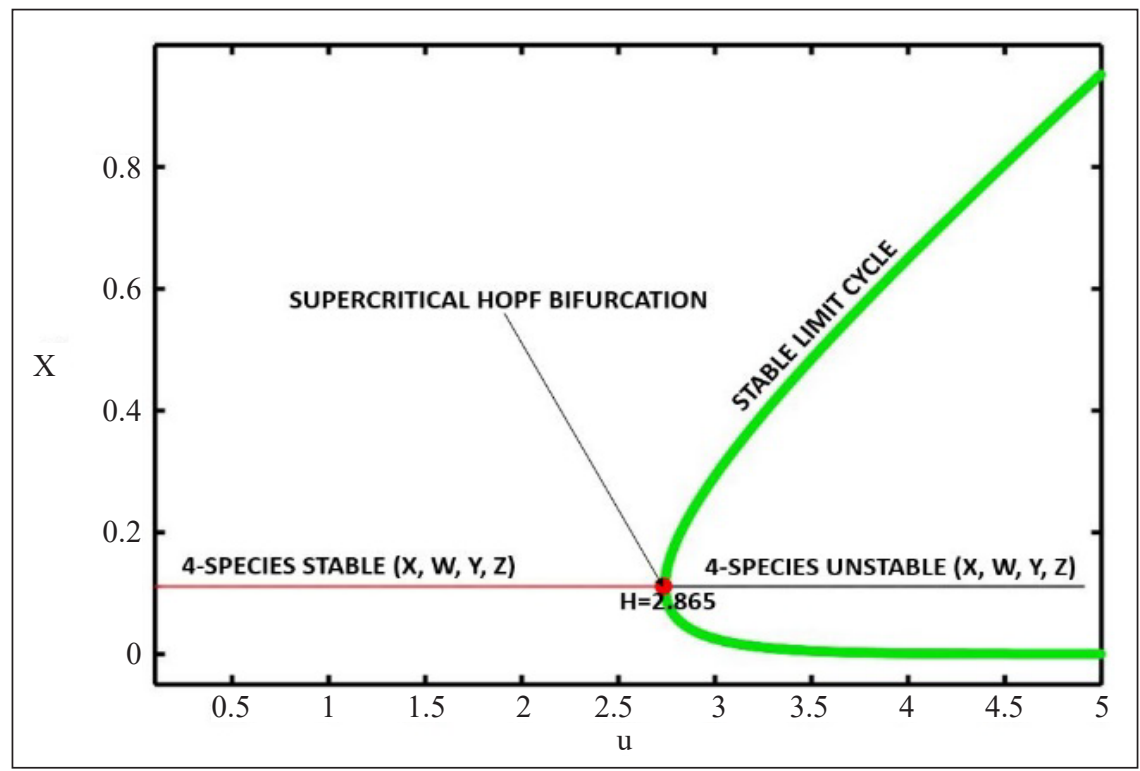

Figure 6. Bifurcation diagram showing the stability behaviour of the system as we vary $\mathrm{u} . \mathrm{D}=0.005$. The diagram was plotted using XPPAUT package and the parameter values in Table 1.

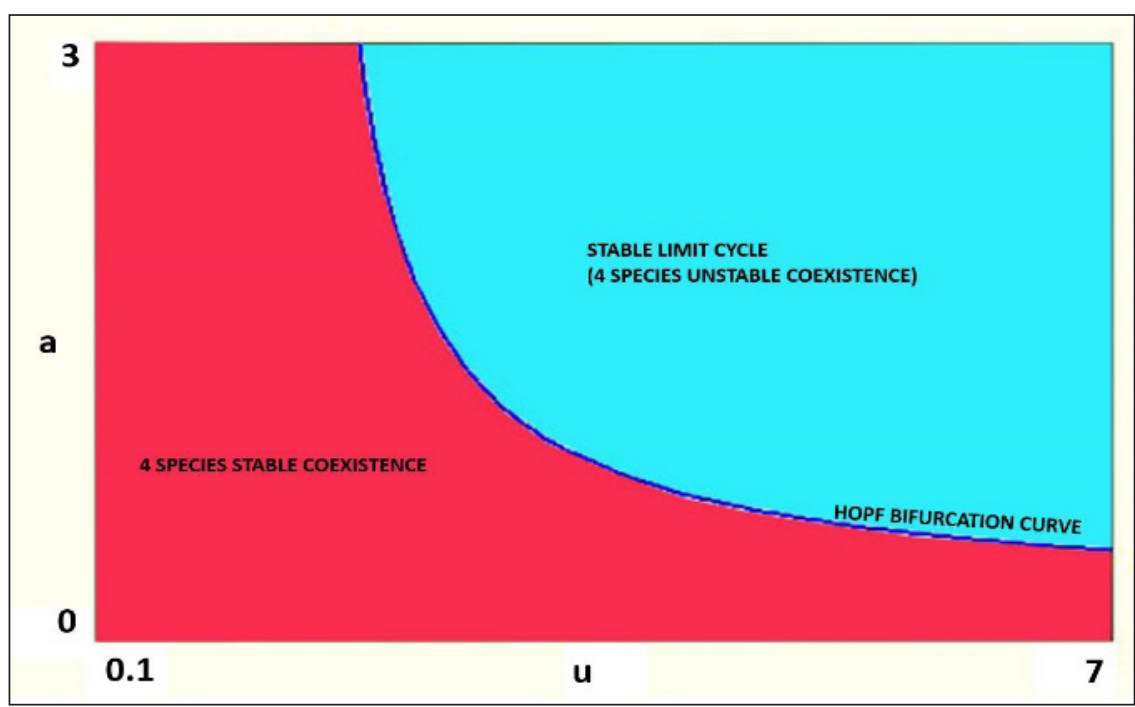

Figure 7. Bifurcation diagram showing the different coexistence dynamics in the system with no-dispersal $(\mathrm{D}=0)$ as a and $\mathrm{u}$ are varied. $\mathrm{D}=0$. The diagram was plotted using XPPAUT package and the parameter values as in Table 1. 


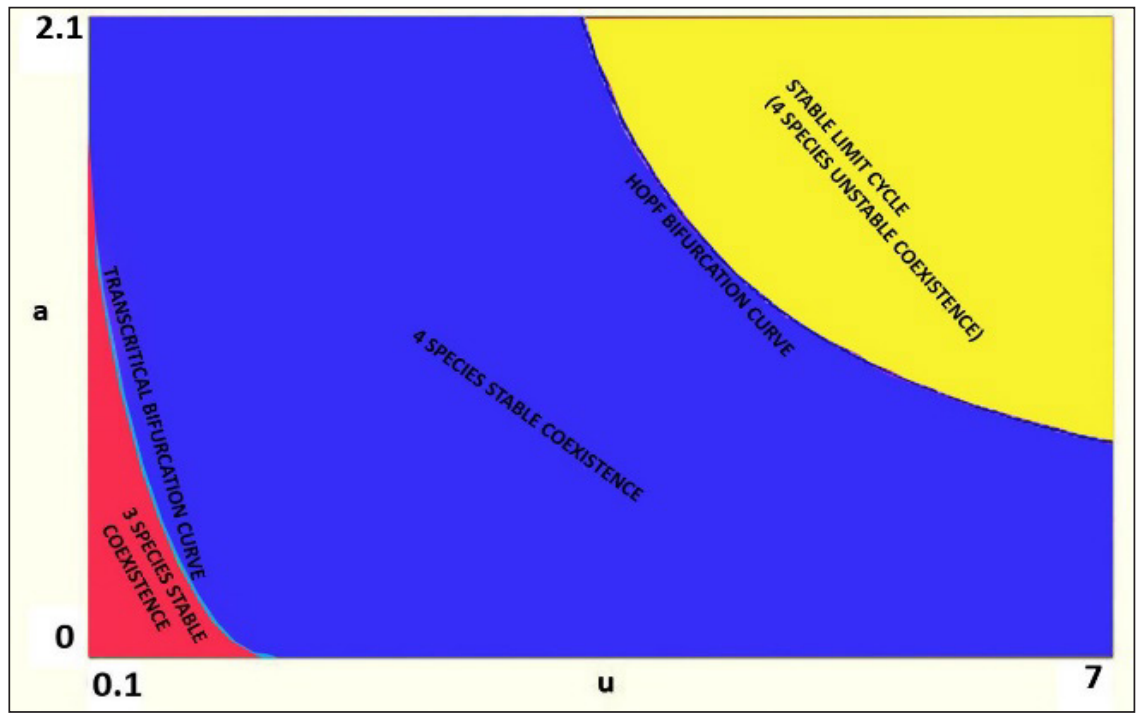

Figure 8. Bifurcation diagram showing the different coexistence dynamics in the PDE system (1) with D=0.005 as a and $u$ were varied. The diagram was plotted using XPPAUT package and the parameter values as in Table 1.

\section{DISCUSSION AND CONCLUSION}

Our numerical simulation results show that the effects of predation, mutualism, and dispersal in the presence of other biotic interactions can affect the community stability and stable coexistence of species in this ecological system. Predation supports the community stability of multiple species in the systems (Caro \& Stoner, 2003). A significant ecological benefit of predation is that it promotes the spatial and structural diversity of species in the ecosystem (Carter et al., 2015; Swanson et al., 2016). Fundamentally, our results show that weak predation strength in a multiple interactions type system affects species diversity negatively in the presence of dispersal. Specifically, weak predation endangers the exploiter species in these multiple species model. Although moderate and intense predation strength supports the stable coexistence and stability of multiple species in this ecological system, there are some conflicting reports on the effects of predation from experimental studies (Cheng et al., 2018; Quinn et al., 2016). We observed that there was a gradual reduction in the equilibrium population densities of the interacting species as the predation strength continued to increase in the absence of dispersal. However, predation can provide a buffer against extinction in the presence of dispersal, even when the interactions are intense. In general, our results show that predation coupled with dispersal in the multiple interactions type model are crucial for species coexistence and persistence.

Mutualism has dual effects on the stability and stable coexistence of the multiple species community. Our results show that for some threshold values of $u$, multiple species stability and persistence can be preserved. For other values of mutualistic strength, the system exhibits oscillatory behaviour. These dual effects of mutualism shown in our results have 
been reported in several studies (Kooi et al., 2004; Valdovinos et al., 2016; Valdovinos et al., 2018; Addicott, 1998; Herrera, 1998; Parker, 1999). Overall, our results provide insights into the significance of mutualism in the understanding of the natural world. We caution that there is a high probability of extinction of species in the occurrence of stable limit cycles as population density continues to fluctuate between some maximum to minimum densities which are close to zero (Mohd, 2019). In contrast to our finding, earlier studies carried out by Rosenzweig (1971) and Wright (1989) reported that mutualism had no impacts on the diversity of species in an ecological system. From the conservation viewpoint, mutualism supports multiple species coexistence for some critical values in this ecological system. This finding is in agreement with the reports that mutualism supports species richness (Pascual-García \& Bastolla, 2017; Chomicki et al., 2019; Bascompte, 2019; Martignoni et al., In Press).

The results in this work also show that dispersal has a qualitative effect on these multiple interactions type model. Dispersal increases the initial amplitude of oscillation in the ecological system. This result is in contrast with the report of (Laan \& Fox, 2019) which observed that dispersal had no effect on the amplitude of oscillation in a multiple interactions type system. The positive effects of dispersal on these multiple interactions type system support the persistence and coexistence mechanisms of species (Kot et al., 1996; Kerr et al., 2002; Mohd et al., 2018). An exciting consequence of dispersal is that it increases the extent of geographical areas for interacting species, and this supports the notion of biodiversity of species (Godsoe et al., 2015; Dytham, 2009). The occurrence of oscillatory behaviour in this system suggests that there are other mechanisms outside the paradox of enrichment that drive population cycle (Rozhnova et al., 2013; Barraquand et al., 2017).

The bifurcation results in this work have demonstrated the role of bifurcation analysis in understanding the coexistence and stability behaviour of a multi-species community. Specifically, our bifurcation result shows the dynamics that occur in this ecological system and the threshold values at which they occur. Furthermore, the bifurcation results illustrate the presence of transcritical and Hopf bifurcation as we vary $a$ and $u$, respectively. The transcritical bifurcation affects the extinction and survival of the exploiter species from the system as a result of stability change, and the Hopf bifurcation causes a transition from a stable steady-state to limit cycles with increasing amplitude over time. These two dynamics have shed some light on the possible outcomes of multiple interactions type system. In particular, our results show that predation, mutualism and dispersal are essential forces that determine the stability and coexistence of multiple species.

In conclusion, the numerical simulations result in this study shows the influential roles of predation, mutualism and dispersal in the maintenance of the multi-species ecological systems. The results in this work will serve as valuable reference material for species conservationists and managers in maintaining the biodiversity of species. 


\section{ACKNOWLEDGEMENT}

This research is supported by the Universiti Sains Malaysia (USM) Fundamental Research Grant Scheme (FRGS) No. 203/PMATHS/6711645.

\section{REFERENCES}

Abbott, K. C. (2011). A dispersal-induced paradox: Synchrony and stability in stochastic metapopulations. Ecology Letters, 14(11), 1158-1169. doi: 10.1111/j.1461-0248.2011.01670.x.

Addicott, J. F. (1979). A multispecies aphid-ant association: Density dependence and species-specific effects. Canadian Journal of Zoology, 57(3), 558-569. doi: 10.1139/z79-066.

Addicott, J. F. (1998). Regulation of mutualism between yuccas and yucca moths: Population level processes. Oikos, 81(1), 119-129. doi: 10.2307/3546474.

Amarasekare, P. (2015). Evolution of dispersal in a multi-trophic community context. Oikos, 125(4), 514-525. doi: 10.1111/oik.02258.

Aslan, C. E., Zavaleta, E. S., Tershy, B., \& Croll, D. (2013). Mutualism disruption threatens global plant biodiversity: A systematic review. PLoS ONE, 8(6), 1-11. doi: 10.1371/journal.pone.0066993.

Barraquand, F., Louca, S., Abbott, K. C., Cobbold, C. A., Cordoleani, F., DeAngelis, D. L., ... \& Murray, D. L. (2017). Moving forward in circles: Challenges and opportunities in modelling population cycles. Ecology Letters, 20(8), 1074-1092. doi: 10.1111/ele.12789.

Bascompte, J. (2019). Mutualism and biodiversity. Current Biology, 29(11), R467-R470. doi: 10.1016/j. cub.2019.03.062.

Bever, J. D. (2003). Soil community feedback and the coexistence of competitors: Conceptual frameworks and empirical tests. New Phytologist, 157(3), 465-473. doi: 10.1046/j.1469-8137.2003.00714.x.

Bjørnstad, O. N. (2000). Cycles and synchrony: Two historical "experiments" and one experience. Journal of Animal Ecology, 69(5), 869-873. doi: 10.1046/j.1365-2656.2000.00444.x.

Bonte, D., Vandenbroecke, N., Lens, L., \& Maelfait, J. P. (2003). Low propensity for aerial dispersal in specialist spiders from fragmented landscapes. Proceedings of the Royal Society of London. Series B: Biological Sciences, 270(1524), 1601-1607. doi: doi.org/10.1098/rspb.2003.2432.

Briggs, C. J., \& Hoopes, M. F. (2004). Stabilizing effects in spatial parasitoid-host and predator-prey models: A review. Theoretical Population Biology, 65(3), 299-315. doi: 10.1016/j.tpb.2003.11.001.

Bronstein, J. L. (2001a). The exploitation of mutualisms. Ecology Letters, 4(3), 277-287. doi: 10.1046/j.14610248.2001.00218.x.

Bronstein, J. L. (2001b). The costs of mutualism. American Zoologist, 41(4), 825-839. doi: 10.1093/icb/41.4.825.

Bruno, J. F., Stachowicz, J. J., \& Bertness, M. D. (2003). Inclusion of facilitation into ecological theory. Trends in Ecology and Evolution, 18(3), 119-125. doi: 10.1016/s0169-5347(02)00045-9.

Caro, T., \& Stoner, C. (2003). The potential for interspecific competition among African carnivores. Biological Conservation, 110(1), 67-75. doi: 10.1016/s0006-3207(02)00177-5. 
Carter, N., Jasny, M., Gurung, B., \& Liu, J. (2015). Impacts of people and tigers on leopard spatiotemporal activity patterns in a global biodiversity hotspot. Global Ecology and Conservation, 3, 149-162. doi: 10.1016/j.gecco.2014.11.013.

Chaianunporn, T., \& Hovestadt, T. (2012). Evolution of dispersal in metacommunities of interacting species. Journal of Evolutionary Biology, 25(12), 2511-2525. doi: 10.1111/j.1420-9101.2012.02620.x.

Chaianunporn, T., \& Hovestadt, T. (2015). Evolutionary responses to climate change in parasitic systems. Global Change Biology, 21(8), 2905-2916. doi: 10.1111/gcb.12944.

Cheng, B. S., Ruiz, G. M., Altieri, A. H., \& Torchin, M. E. (2018). The biogeography of invasion in tropical and temperate seagrass beds: Testing interactive effects of predation and propagule pressure. Diversity and Distributions, 25(2), 285-297. doi: 10.1111/ddi.12850.

Chesson, P. (2000). Mechanisms of maintenance of species diversity. Annual Review of Ecology and Systematics, 31(1), 343-366. doi: 10.1146/annurev.ecolsys.31.1.343.

Chesson, P., \& Kuang, J. J. (2008). The interaction between predation and competition. Nature, 456(7219), 235-238. doi: 10.1038/nature07248.

Chomicki, G., Weber, M., Antonelli, A., Bascompte, J., \& Kiers, E. T. (2019). The impact of mutualisms on species richness. Trends in Ecology and Evolution, 34(8), 698-711. doi: doi.org/10.1016/j.tree.2019.03.003.

Dey, S., \& Joshi, A. (2006). Stability via asynchrony in drosophila metapopulations with low migration rates. Science, 312(5772), 434-436. doi: 10.1126/science.1125317.

Dytham, C. (2009). Evolved dispersal strategies at range margins. Proceedings of the Royal Society B: Biological Sciences, 276(1661), 1407-1413. doi: 10.1098/rspb.2008.1535.

Fontaine, C., Guimarães Jr, P. R., Kéfi, S., Loeuille, N., Memmott, J., van Der Putten, W. H., ... \& Thébault, E. (2011). The ecological and evolutionary implications of merging different types of networks. Ecology Letters, 14(11), 1170-1181. doi: 10.1111/j.1461-0248.2011.01688.x.

Gause, G. F., \& Witt, A. A. (1935). Behavior of mixed populations and the problem of natural selection. The American Naturalist, 69(725), 596-609. doi: 10.1086/280628.

Georgelin, E., \& Loeuille, N. (2014). Dynamics of coupled mutualistic and antagonistic interactions, and their implications for ecosystem management. Journal of Theoretical Biology, 346, 67-74. doi: 10.1016/j. jtbi.2013.12.012.

Godsoe, W., Murray, R., \& Plank, M. J. (2015). Information on biotic interactions improves transferability of distribution models. The American Naturalist, 185(2), 281-290. doi: 10.1086/679440.

Green, D. M. (2009). Coevolution of dispersal in a parasitoid-host system. Population Ecology, 51(2), 253260. doi: 10.1007/s10144-008-0131-3.

Hanski, I. (1998). Metapopulation dynamics. Nature, 396(6706), 41-49. doi: 10.1038/23876.

Herrera, C. M. (1998). Long-term dynamics of Mediterranean Frugivorous birds and fleshy fruits: A 12-year study. Ecological Monographs, 68(4), 511-538. doi: 10.1890/0012-9615(1998)068[0511:1tdomf]2.0.c.

Hixon, M. A., \& Menge, B. A. (1991). Species diversity: Prey refuges modify the interactive effects of predation and competition. Theoretical Population Biology, 39(2), 178-200. doi: 10.1016/0040-5809(91)90035-e. 
Holland, J. N., \& DeAngelis, D. L. (2010). A consumer-resource approach to the density-dependent population dynamics of mutualism. Ecology, 91(5), 1286-1295. doi: 10.1890/09-1163.1.

Holland, J. N., DeAngelis, D. L., \& Bronstein, J. L. (2002). Population dynamics and mutualism: Functional responses of benefits and costs. The American Naturalist, 159(3), 231-244. doi: 10.1086/338510.

Holland, J. N., Wang, Y., Sun, S., \& DeAngelis, D. L. (2013). Consumer-resource dynamics of indirect interactions in a mutualism-parasitism food web module. Theoretical Ecology, 6(4), 475-493. doi: 10.1007/s12080-013-0181-9.

Johnson, C. N., Isaac, J. L., \& Fisher, D. O. (2007). Rarity of a top predator triggers continent-wide collapse of mammal prey: Dingoes and marsupials in Australia. Proceedings of the Royal Society B: Biological Sciences, 274(1608), 341-346. doi: 10.1098/rspb.2006.3711.

Kendall, B. E., Bjørnstad, O. N., Bascompte, J., Keitt, T. H., \& Fagan, W. F. (2000). Dispersal, environmental correlation, and spatial synchrony in population dynamics. The American Naturalist, 155(5), 628-636. doi: $10.1086 / 303350$.

Kerr, B., Riley, M. A., Feldman, M. W., \& Bohannan, B. J. M. (2002). Local dispersal promotes biodiversity in a real-life game of rock-paper-scissors. Nature, 418(6894), 171-174. doi: 10.1038/nature00823.

Kindlmann, P., \& Burel, F. (2008). Connectivity measures: A review. Landscape Ecology, 23(8), 879-890. doi: $10.1007 /$ s10980-008-9245-4.

Kooi, B. W., Kuijper, L. D. J., \& Kooijman, S. A. L. M. (2004). Consequences of symbiosis for food web dynamics. Journal of Mathematical Biology, 49(3), 227-271. doi: 10.1007/s00285-003-0256-0.

Kool, J. T., Moilanen, A., \& Treml, E. A. (2012). Population connectivity: Recent advances and new perspectives. Landscape Ecology, 28(2), 165-185. doi: 10.1007/s10980-012-9819-z.

Kot, M., Lewis, M. A., \& van den Driessche, P. (1996). Dispersal data and the spread of invading organisms. Ecology, 77(7), 2027-2042. doi: 10.2307/2265698.

Laan, E., \& Fox, J. W. (2019). An experimental test of the effects of dispersal and the paradox of enrichment on metapopulation persistence. Oikos, 129(1), 49-58 doi: 10.1111/oik.06552.

Lampert, A., \& Hastings, A. (2016). Stability and distribution of predator-prey systems: Local and regional mechanisms and patterns. Ecology Letters, 19(3), 279-288. doi: 10.1111/ele.12565.

Martignoni, M. M., Hart, M. M., Tyson, R. C., \& Garnier, J. (In Press). Diversity within mutualist guilds promotes coexistence and reduces the risk of invasion from an alien mutualist. Proceedings of the Royal Society B: Biological Sciences. doi: 10.1098/rspb.2019.2312.

Mitani, N., \& Mougi, A. (2017). Population cycles emerging through multiple interaction types. Royal Society Open Science, 4(9), 1-7. doi: 10.1098/rsos.170536.

Mohd, M. H. (2019). Diversity in interaction strength promotes rich dynamical behaviours in a three-species ecological system. Applied Mathematics and Computation, 353, 243-253. doi: 10.1016/j.amc.2019.02.007.

Mohd, M. H., Murray, R., Plank, M. J., \& Godsoe, W. (2017). Effects of biotic interactions and dispersal on the presence-absence of multiple species. Chaos, Solitons and Fractals, 99, 185-194. doi: 10.1016/j. chaos.2017.04.012. 
Mohd, M. H., Murray, R., Plank, M. J., \& Godsoe, W. (2018). Effects of different dispersal patterns on the presence-absence of multiple species. Communications in Nonlinear Science and Numerical Simulation, 56, 115-130. doi: 10.1016/j.cnsns.2017.07.029.

Mondor, E. B., Rosenheim, J. A., \& Addicott, J. F. (2004). Predator-induced transgenerational phenotypic plasticity in the cotton aphid. Oecologia, 142(1), 104-108. doi: 10.1007/s00442-004-1710-4.

Morales, M. A. (2000). Mechanisms and density dependence of benefit in an ant-membracid mutualism. Ecology, 81(2), 482-489. doi: 10.1890/0012-9658(2000)081[0482:MADDOB]2.0.CO;2.

Ojonubah, J. O., \& Mohd, M. H. (2020). Impacts of asymmetric biotic interactions and environmental factors on the presence-absence of multispecies. Pertanika Journal of Science and Technology, 28(1), 245-261.

Parker, M. A. (1999). Mutualism in metapopulations of legumes and rhizobia. The American Naturalist, 153(S5), S48-S60. doi: 10.1086/303211.

Pascual-García, A., \& Bastolla, U. (2017). Mutualism supports biodiversity when the direct competition is weak. Nature Communications, 8(1), 1-13. doi: 10.1038/ncomms14326

Poethke, H. J., Weisser, W. W., \& Hovestadt, T. (2010). Predator-induced dispersal and the evolution of conditional dispersal in correlated environments. The American Naturalist, 175(5), 577-586. doi: $10.1086 / 651595$.

Quinn, T. P., Cunningham, C. J., \& Wirsing, A. J. (2016). Diverse foraging opportunities drive the functional response of local and landscape-scale bear predation on Pacific salmon. Oecologia, 183(2), 415-429. doi: $10.1007 / \mathrm{s} 00442-016-3782-3$.

Rosenzweig, M. L. (1971). Paradox of enrichment: Destabilization of exploitation ecosystems in ecological time. Science, 171(3969), 385-387. doi: 10.1126/science.171.3969.385.

Rosenzweig, M. L., \& MacArthur, R. H. (1963). Graphical representation and stability conditions of predatorprey interactions. The American Naturalist, 97(895), 209-223. doi: 10.1086/282272.

Rozhnova, G., Metcalf, C. J. E., \& Grenfell, B. T. (2013). Characterizing the dynamics of rubella relative to measles: The role of stochasticity. Journal of The Royal Society Interface, 10(88), 20130643-20130643. doi: 10.1098/rsif.2013.0643.

Sala, E. (2006). Top predators provide insurance against climate change. Trends in Ecology and Evolution, 21(9), 479-480. doi: 10.1016/j.tree.2006.07.006.

Schmitt, R. J., \& Holbrook, S. J. (2003). Mutualism can mediate competition and promote coexistence. Ecology Letters, 6(10), 898-902. doi: 10.1046/j.1461-0248.2003.00514.x.

Schmitz, O. J. (2006). Predators have large effects on ecosystem properties by changing plant diversity, not plant biomass. Ecology, 87(6), 1432-1437. doi: 10.1890/0012-9658(2006)87[1432:phleoe]2.0.co;2.

Soulé, M. E., \& Terborgh, J. (1999). Conserving nature at regional and continental scales-a scientific program for North America. BioScience, 49(10), 809-817. doi: 10.2307/1313572.

Steiner, C. F., Stockwell, R. D., Kalaimani, V., \& Aqel, Z. (2013). Population synchrony and stability in environmentally forced metacommunities. Oikos, 122(8), 1195-1206. doi: 10.1111/j.16000706.2012.20936.x. 
Swanson, A., Arnold, T., Kosmala, M., Forester, J., \& Packer, C. (2016). In the absence of a "landscape of fear": How lions, hyenas, and cheetahs coexist. Ecology and Evolution, 6(23), 8534-8545. doi: 10.1002/ ece3.2569.

Valdovinos, F. S., Berlow, E. L., Moisset de Espanés, P., Ramos-Jiliberto, R., Vázquez, D. P., \& Martinez, N. D. (2018). Species traits and network structure predict the success and impacts of pollinator invasions. Nature Communications, 9(1), 1-8. doi: 10.1038/s41467-018-04593-y.

Valdovinos, F. S., Brosi, B. J., Briggs, H. M., Moisset de Espanés, P., Ramos-Jiliberto, R., \& Martinez, N. D. (2016). Niche partitioning due to adaptive foraging reverses effects of nestedness and connectance on pollination network stability. Ecology Letters, 19(10), 1277-1286. doi: 10.1111/ele.12664.

Vasseur, D. A., \& Fox, J. W. (2009). Phase-locking and environmental fluctuations generate synchrony in a predator-prey community. Nature, 460(7258), 1007-1010. doi: 10.1038/nature08208.

Vogwill, T., Fenton, A., \& Brockhurst, M. A. (2009). Dispersal and natural enemies interact to drive spatial synchrony and decrease stability in patchy populations. Ecology Letters, 12(11), 1194-1200. doi: 10.1111/j.1461-0248.2009.01374.x.

Wright, D. H. (1989). A simple, stable model of mutualism incorporating handling time. The American Naturalist, 134(4), 664-667. doi: 10.1086/285003.

Yaari, G., Ben-Zion, Y., Shnerb, N. M., \& Vasseur, D. A. (2012). Consistent scaling of persistence time in metapopulations. Ecology, 93(5), 1214-1227. doi: 10.1890/11-1077.1.s. 
